I observe there is a discussion regarding the canula for tracheotomy. It should, of course, be sufficiently large to admit of easy respiration, but there ought to be some plan of diminishing the size of the opening, to enable the patient to cough-or rather to imitate coughing, and throw out secretion from the lungs. Through a full-sized tube the patient cannot expectorate, but diminishing the opening of the canula one-half or more, after a full inspiration, and forcibly expiring, expectoration will be thrown out. I believe death after tracheotomy is often caused by this inability to expectorate. I had a double canula constructed, the upper tube projecting, to be stopped by the finger; but, fortunately, I have never required it.

Can you explain why the os uteri, in cases of turning, when one foot only is brought down, should sometimes contract round the thigh of the child, retarding delivery, or impeding it altogether, till the hand is again introduced, and the os re. dilated? In three cases this has occurred to me, one of them being the case above mentioned. If it falls to my lot again to turn a child, I shall not be satisfied with one foot, as I was taught, aud I believe is generally recommended by authors on midwifery. The loss of time and risk in finding the second foot can be nothing in comparison with that from this contraction, unless its cause and means of prevention were known.

I have the honour to be, Sir, most respectfully and gratefully,

To Dr. Marshall Hall.

$$
\text { Your very obedient servant, }
$$

$$
\text { H. Craigie. }
$$

\section{CHOLERA AMONGST CATTLE.}

\section{To the Editor of THE LANCET.}

SrR, - I beg to call your attention, and that of the authorities, through your journal, to a virulent attack of cholera amongst pigs and cattle in my neighbourhood. Having heard that a number of pigs belonging to a gentleman here had died, and that the cause of death was unknown, I went and saw one which had been taken ill a short time previous. It was lying on its side in a state of collapse, eyes dull, ears hanging back, vagina hanging out, pale and flabby. On being disturbed, it uttered a peculiar, low, wailing cry. The belly was of a beautiful pink colour, shaded with blue; on some parts of the body the blue colour approached to a black. On turning it over, the side which was lying on the ground was of its natura colour, (white, ) showing, I think, that exposure to the air had something to do with the change of colour. At intervals it was much cramped, and the soft fæces were jerked to a little distance. It had also vomited, and its month was filled with a grumous fluid. Various remedies were tried, which gave it increased strength, but with return of strength came increased violence of cramps, and it died after six hours' illness. I opened it next day. The post-mortem appearances wereflaccidity of body; surface a dark blue, with a pinkish tint on belly; stomach moderately distended with half-digested food, studded with patches of inflammation varying in size from a shilling to a half-crown, the intervals being natural in colour; the small intestines at intervals of about eight to twelve inches were inflamed, the length of inflamed part about an inch; large intestines healthy; liver and spleen natural; heart natural. The lungs alone presented features which arrested the eye-namely, from the intense scarlet colour of their surface and of every part cut into; they were not congested, but conld be expanded fully with the blow-pipe, collapsing when untied. Eight have died since that (the 3 rd inst.) 'The keeper informed me that they had lost about forty since the disease appeared. At first it began like influenza or intestinal fever; fever, prostration, constipation, loss of power in the legs, and they lingered a long time; now the disease is different, and they die after a few hours' illness. The long ranges of buildings are badly ventilated and not drained. I felt suffocated while walking through them, and there was a depth of six inches of putrid water under the plank on which $I$ walked.

On Saturday last, I visited another farm where three cattle had died, one clearly from lung disease, and two from choleroid disease, from the cramps and few hours' illness.

I shall make no comments further than to sny, that a great and heavy responsibility lies on our authorities, inasmuch as no provision has been made to supply the farmer with efficient skill for investigating the nature, treatment, and prevention of those diseases; and further, that when an animal dies after such a short illness, to the ordinary eye there is no change to be seen in the meat when cut up. I know to a certainty that diseased carcases daily find their way to the towns, and are there consumed by the unsuspecting public. In short, nothing but skill of a high order, with auxiliaries not at present in use, can detect such meat.

I remain, Sir, your obedient servant,

WM. McDonald, M.R.C.S. Surgeon to the Heathfield, Bedlay, and Shankramuir Works,
and Medical Officer for Cadder parish.

Chryston, June, 1857,

\section{THE STAFF AND THE COMMITTEE OF THE NORWICH AND NORFOLK HOSPITAL.}

\section{To the Editor of THE LANCET.}

SIR,-The question of admitting patients suffering from the earlier forms of venereal disease has been recently brought before the governors of the Norfolk and Norwich Hospital, and at a general meeting held in March last, it was determined, on the motion of one of the surgical staff, and carried by a large majority of the governors present, that for the future such cases should be eligible for admission and treatment. A sub-committee, composed of the medical staff and the weekly board, was appointed to carry out the details of the resolution, with instructions to report at the next general meeting. It is generally understood amongst those interested in this movement, that a great difference of opinion exists between the members of this joint committee, and that the medical staff who are anxious to see the resolution of the general meeting fairly carried out, are opposed by a large majority of the weekly board, whose feelings appear to be adverse to the admission of such cases into the hospital at all. Two causes appear to influence this opposition-viz, probable increased expenditure, and the influence which the presence of such cases might have upon the morale of the patients, nurses, \&c. The question at present remains in abeyance, and will probably form a subject of renewed discussion at the next general meeting. In the meantime, as a non-medical governor, anxious to be rightly guided in giving my vote, I submit the above facts to you.

I should naturally suppose that suffering huranity, although the result of vicious indulgence, would, per se, have a demand upon the sympathies of those who govern this hospital; and, before I give my vote, I should be glad to be informed as to the course adopted in other hospitals, not wishing to be led away by a morbid sympathy for the vicious and their suffering, and at the same time to guard myself against becoming the supporter of a party whose Christian charity would appear to be warped by intolerance and bigotry.

An exposition of your sentiments upon this important subject would oblige, and guide not only myself, but many other governors. I am, Sir, yours obediently,

Catton, near Norwich, A GoverNor of THE NorwICH AND June, 1857. Norfolk Hospital.

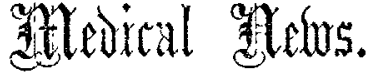

Royal Colnege of Surgens.-The following gentlemen, having undergone the necessary examinations for the Diploma, were admitted members of the College at the meeting of the Court of Examiners on the 22th inst.:-

Adam, EDWard, Dublin.

AGAR, WAlter JAMES, Cork.

Cathin, George Taylor, Islington

Egan, Charles James, Dublin.

Fisher, Willtam Shute, Charleville, co. Cork.

Hobson, George William, Aberdeen.

Hughes, Roger, Bala, North Wales.

Shooter, Charles, Bishop Wilton, Yorkshire.

Apothecaries' Hatr. - Names of gentlemen who passed their examination in the science and practice of Medicine, and received certificates to practise, on

Thursday, June 11 th, 1857.

Barnes, James Hindmansh, Bath.

Bird, William, Stroud, Gloucestershire.

Curran, William, Youghal, Ireland.

Hetrrington, Josepir, Lampleigh Hall, Sunderland.

Jeaffresoy, George Edward, Framlingham, Suffolk.

Marshall, Alexander Wilson, Birkenhead.

Pore, Joserh JoHn, Liverpool.

Rees, Hugh, Carnarvon.

Vinrace, John, Ashby-de-la-Zouch.

Watkins, John WebB. 